(c) American Dairy Science Association, 2004.

\title{
Trace of Native Cattle in Japanese Holstein Assessed by Mitochondrial DNA Sequence Polymorphism
}

\author{
S. Tsuji, ${ }^{1}$ H. Mannen, ${ }^{1}$ F. Mukai, ${ }^{1}$ M. Shojo, ${ }^{2}$ K. Oyama, ${ }^{1}$ T. Kojima, ${ }^{2}$ \\ C. Kano, ${ }^{2}$ Y. Kinoshita, ${ }^{3}$ and E. Yamaguchi ${ }^{4}$ \\ ${ }^{1}$ Faculty of Agriculture and \\ ${ }^{2}$ Graduate School of Science and Technology, \\ Kobe University, Kobe 657-8501, Japan \\ ${ }^{3}$ Mineoka Dairy Experimental Station, Maruyama-cho, Awagun, \\ Chiba, 299-2507, Japan \\ ${ }^{4}$ Wadayama Livestock Hygiene Service Center, Wadayama-cho, \\ Asakogun, Hyogo 669-5243, Japan
}

\begin{abstract}
On the basis of sequence variation in the displacement loop region of mtDNA, 588 Japanese and North American Holstein cows were classified into 5 mitochondrial haplotypes, which were found in Japanese Black cattle. One of the haplotypes (named type 1), which was present at the highest frequency in Japanese Black cattle, was not observed in either European or African cattle. This haplotype is characterized by 2 single-nucleotide polymorphisms. One is called the type B polymorphism, and it refers to a base change from $\mathrm{T}$ to $\mathrm{C}$ at nucleotide 16042 of the mitochondrial genome (T160042C). The other is called the type I polymorphism, and it refers to the base change as G16093A. The proportion of the Japanese Holstein population with both polymorphisms was $18.3 \%$, whereas none of the North American cows had this genotype. Because the mitochondrial types were inherited maternally, it is clear that a considerable number of Japanese Holstein cows are descended from native Japanese cattle. Polymorphisms B and I accounted for no variance in the estimated breeding value for milk production among cows from the Hyogo herd (582 cows) or the Chiba region herd (758 cows). This result suggests that most autosomal genes of native animals have been successively replaced by those of pure Holstein after grading up of over 15 generations, even though resulting animals have native animal-oriented mitochondrial types and may still have some number of the native autosomal genes.
\end{abstract}

(Key words: D-loop, grading up, Japanese HolsteinFriesian)

Abbreviation key: D-loop = displacement loop region of mtDNA.

Received June 4, 2003.

Accepted September 9, 2003.

Corresponding author: S. Tsuji; e-mail: tsuji@ans.kobe-u.ac.jp.

\section{INTRODUCTION}

From the 1600s to the mid-1800s, the borders of Japan were closed to importation by the feudal government. Imperial power was restored and the new Meiji era was established in 1868. Since then, Japan has opened its lands and allowed Western countries to introduce new technology and culture. This occurred for dairy farming as well as other agricultural enterprises. At that time, farmers had no cattle for milk production and no money to purchase elite bulls or cows from those countries, so the government took the initiative of introducing elite animals. The first breeding stock of Holstein-Friesian was introduced in 1889 from the United States and the Netherlands. The objective was to increase milk production, and the government recommended grading up for native cows.

In Japan, we have native cattle called "Wagyu". Some of their descendants are now called Japanese Black cattle, a major beef breed of Japan. Our group has previously analyzed the displacement loop region of mtDNA (D-loop) sequences of the Japanese Black breed and found that animals could be classified into 5 haplotypes, one of which (type 1 ) is derived from the native cows, and is only observed in Japanese Black cattle (Mannen et al., 1998b).

The present study involved 2 separate experiments. The first used an initial sample of animals to characterize genotypes present in the Japanese Holstein population and to compare these with genotypes observed in North America. The analysis showed the presence of native mtDNA, suggesting that the native cows had graded up with Holstein sires. The second experiment compared modern performance traits between native and pure mitochondrial origins using a larger group of animals to investigate whether this grading up has been successful with native cows. 


\section{MATERIALS AND METHODS}

\section{Animals}

A total of 591 cows was used for the first experiment investigating the genotypes that exist in the mitochondrial genome. They comprised 100 cows in Hokkaido, 102 in Chiba, 222 in Hyogo, 55 in the United States (Utah State University), and 112 in Canada (University of Guelph). The 424 cows from Japan were randomly sampled and the cows from the United States had different maternal lineages. The samples from Hyogo were divided into cows from the mainland (Hyogo 1) and cows from Awaji Island (Hyogo 2), where many cows are kept.

For the second experiment, 763 cows in Chiba and 588 cows in Hyogo were sampled. These were genotyped, and the association between milk production traits and mitochondrial haplotypes was analyzed. The samples were collected from 39 and 36 randomly chosen farms in Chiba and Hyogo, respectively, and restricted to those having EBV because EBV were used as measures of milk production traits.

\section{Genotyping}

$\boldsymbol{P C R}$ - RFLP. Hair roots were used as a source of DNA for this study. Several 3-mm-long hair with intact roots were treated in a microwave for $5 \mathrm{~min}$ in a $0.5-\mathrm{ml} \mathrm{Ep}$ pendorf tube (Higuchi et al., 1988; Thomson et al., 1992). After treatment, $14.3 \mu \mathrm{L}$ of distilled water, $1 \mu \mathrm{L}$ of reverse and forward primers, $2 \mu \mathrm{L}$ of Taq buffer, $1.6 \mu \mathrm{L}$ of dNTP mixture, and $0.1 \mu \mathrm{L}$ Takara Ex-Taq hot start ( $5 \mathrm{U} / \mu \mathrm{L}$ ) were added. Then, PCR reactions started at $94^{\circ} \mathrm{C}$ for $2 \mathrm{~min}$, followed by 40 cycles of $90^{\circ} \mathrm{C}$ for $30 \mathrm{~s}$, $60^{\circ} \mathrm{C}$ for $30 \mathrm{~s}, 72^{\circ} \mathrm{C}$ for $1 \mathrm{~min}$, and a final extension of $72^{\circ} \mathrm{C}$ for 7 min using a Takara PCR Thermal cycler 480 (Tokara, Tokyo, Japan). A fragment of the D-loop, nt16008 to nt16160, was amplified using primers ACATTAAATTATATGCCCCATGC and AGCTCGTGATCTAATGGTAAGGA.

There are $4 R s a$ I restriction sites within the amplified fragment, as shown in Figure 1a. To the $2.5-\mu \mathrm{L}$ aliquots of PCR product, $1.5 \mu \mathrm{L}$ of $10 \times$ buffer, $10.75 \mu \mathrm{L}$ of distilled water, and $0.25 \mu \mathrm{L}$ of $R s a \mathrm{I}$ ( $8 \mathrm{U}$ ) were added and then incubated for $4 \mathrm{~h}$ at $37^{\circ} \mathrm{C}$ for digestion. The digested samples were boiled after adding $3 \mu \mathrm{L}$ of formamide and then immediately cooled. Using $40 \mathrm{~cm} \times 25 \mathrm{~cm} \times 0.4 \mathrm{~mm}$ polyacrylamide gel $(6 \%)$ containing $8 M$ urea, digested samples were analyzed at $1800 \mathrm{~V}$ for $40 \mathrm{~min}$. The DNA fragments were visualized using a silver-staining method through the Silver Sequence DNA Sequencing System (Promega, Madison, WI).

\section{Sequencing}

For 153-bp fragments that could not be classified by the PCR-RFLP method, DNA sequences were deter- mined after extraction of the fragment from $2 \%$ agarose gels using Gene Mate DNA purification kit (Promega). Sequencing was carried out using the Silver Sequence DNA sequencing system (Promega). Primers were the same as those used for the PCR reaction.

\section{Statistical Analysis}

Comparison of milking performance between mitochondrial haplotypes was carried out using 2-way ANOVA on EBV obtained from 2 regions. The statistical model included the region and haplotype as fixed effects. The traits analyzed were milk yield $(\mathrm{kg})$, protein $(\mathrm{kg}$, $\%)$, fat $(\mathrm{kg}, \%)$, and SNF (kg, \%). The EBV of cows were provided by the National Livestock Breeding Center (Fukushima).

\section{RESULTS AND DISCUSSION}

\section{Genotyping}

In our previous study, analysis of the D-loop region revealed 5 mitochondrial haplotypes in Japanese Black cattle (Mannen et al., 1998b). One of the haplotypes was observed only in the Japanese cattle. This haplotype is characterized by 2 single-nucleotide polymorphisms. Mannen et al. (1998b) have defined that the type B polymorphism is a base change from $\mathrm{T}$ to $\mathrm{C}$ at nucleotide 16042 of the mitochondrial genome (T160042C) and that the type I polymorphism is a base change of G16093A.

Figure 1 shows a PCR-RFLP pattern of amplified mtDNA on a polyacrylamide gel. Three fragments (73, 66 , and $54 \mathrm{bp}$ ) were visible on the gel. Combinations of the fragments show 4 polymorphism types in which the type I polymorphism has only one 73-bp fragment, the type B polymorphism has 66- and 54-bp fragments, the type BI polymorphism has 73- and 54-bp fragments, and the type S polymorphism has only one fragment of 66 bp. Using this classification, the genotypes of 588 cows from 4 districts of Japan and 2 areas of North America were determined (Table 1). Genotypes of 3 of the 591 cows could not be classified into the aforementioned types using the PCR-RFLP method, so the DNA sequence of the $153 \mathrm{bp}$ (nt16008 to nt16160), including the polymorphic sites of B and I, was determined. Compared with the data of Anderson et al. (1982), 2 out of 3 animals showed a substitution of $\mathrm{G}$ for $\mathrm{A}$ at nt16056. One of 3 showed a deletion of 3 nucleotides (TAT) from nt16128. Those 3 animals were removed because their polymorphisms were different from the ones specific to the above types.

As shown in Table 1, 96\% of North American cows were classified into type $\mathrm{S}$, which is defined as a standard sequence, as described by Anderson et al. (1982). The frequencies of type B and type I polymorphisms 
$\mathbf{a}$
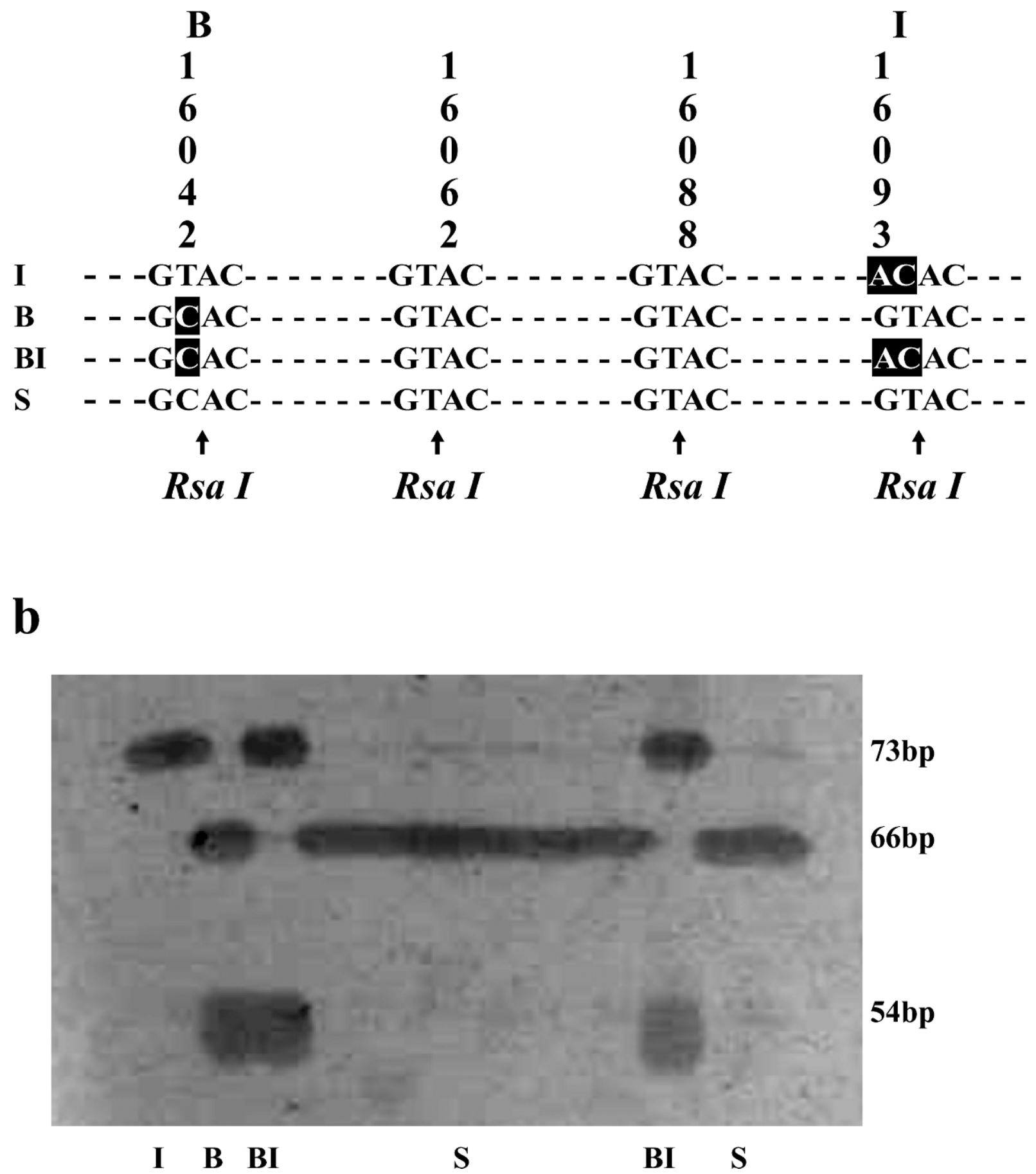

Figure 1. Four Rsa I restriction sites and its mutations of the displacement loop region of mtDNA (D-loop) between nt16008 to nt16160 (a). Patterns of mtDNA variation by PCR-RFLP on polyacrylamide gel (b). Numbers on the right column reflect the size of the DNA fragment (bp). Symbols at the bottom represent mutation types of D-loop region. An amplified fragment from nt16008 to nt16160 of the D-loop region was digested by $R s a$ I and electrophoresed on a 6\% polyacrylamide sequencing gel containing $8 M$ urea. 
Table 1. Mitochondrial sequence polymorphism frequency in different herds.

\begin{tabular}{lrcccc}
\hline Region & $\mathrm{N}$ & $\begin{array}{c}\text { Polymorphism } \\
\text { BI type, } \%\end{array}$ & S type, $\%^{1}$ & $\begin{array}{c}\text { Polymorphism } \\
\text { B type, \% }\end{array}$ & $\begin{array}{c}\text { Polymorphism } \\
\text { I type, \% }\end{array}$ \\
\hline Hokkaido & 99 & 34.3 & 64.6 & 1.0 & 0.0 \\
Chiba & 102 & 8.8 & 87.3 & 2.9 & 1.0 \\
Hyogo 1 & 119 & 19.3 & 77.3 & 4.2 & 0.0 \\
Hyogo 2 & 101 & 11.9 & 63.4 & 23.8 & 1.0 \\
Subtotal & 421 & 18.3 & 73.4 & 7.8 & 3.5 \\
USA $^{2}$ & 55 & 0.0 & 90.9 & 5.5 & 0.0 \\
Canada $^{3}$ & 112 & 0.0 & 98.2 & 1.8 & 1.2 \\
Subtotal & 167 & 0.0 & 95.8 & 3.0 & \\
\hline
\end{tabular}

${ }^{1}$ Standard type: animals with the same sequence as presented by Anderson et al. (1982).

${ }^{2} \mathrm{~A}$ herd from Utah State University.

${ }^{3} \mathrm{~A}$ herd from University of Guelph, Canada.

were very low $(\leq 3 \%)$. The Holstein breed originated from the area that borders the Netherlands and Germany. Until now, no animals having both the type B and type I polymorphism had been observed in breeds of European origin including Holstein-Friesian (Loftus et al., 1994a, 1994b; Bradley et al., 1996). Although type $\mathrm{S}$ indicated the highest frequencies in all regions, the $\chi^{2}$ value showed that there was a significant difference in genotype frequency distribution between North America and Japan.

In this study, the type BI polymorphism had a frequency of $34.3 \%$ in the Hokkaido region, $19.3 \%$ in the Hyogo 1 region, and $11.9 \%$ in the Hyogo 2 region. In the Chiba region, its frequency was only $8.8 \%$. It is interesting that the cows from Chiba have the lowest value. The type $\mathrm{B}$ polymorphism appears infrequently in most regions of Japan, but the frequency in Hyogo 2 was $23.8 \%$. This can be explained by the unexpected observation that all cows from one particular farm in Hyogo 2 had the same mitochondrial genotype: the type B polymorphism.

Animals with the type B and I polymorphisms (i.e., type 1), are restricted to the Japanese Black breed (Mannen et al., 1998b). Average frequency of this type is $18 \%$ in Japanese Holstein and $0 \%$ in North American Holsteins. This result suggests that in spite of $120 \mathrm{yr}$ of grading up by the use of purebred Holstein bulls and cows, a considerable number of Japanese Holsteins have descended directly from female animals in the native population and have retained the unique mtDNA of these cows. The frequency of the BI genotype differs between regions in Japan ( 8.8 to $34.3 \%$ ), reflecting the history of the breed. Although no precise record could be found, it has been reported that a large number of animals (approximately 2000 to 3000 animals) were transferred from Chiba to Hokkaido in 1920s and 1930 s, and Chiba replaced those animals with imported pure cows (The Holstein Cattle Association in Japan,
1967). The highest number (34.3\%) in Hokkaido and the lowest value in Chiba could reflect this event.

If the native cow of the Meiji era showed the same frequency of the type BI polymorphism as the present Japanese Black cows, the frequency should be $60 \%$ (Mannen et al. 1998a,b). When the resulting type BI frequency of present Japanese Holstein is $34 \%$, it can be estimated that $57 \%(0.34 / 0.60)$ of the Holstein cows are descended from native cows. When the BI frequency is assumed to be $9 \%, 15 \%$ of cows are descendants of native cows. Therefore, from Table 1 , it is suggested that 15 to $57 \%$ of Japanese Holstein cows are the descendants of native cows, but this proportion differs among regions in Japan. In any case, this result clearly shows that the Japanese Holstein is different from the North American Holstein in the sense of mitochondrial genotypes as the result of grading up over $120 \mathrm{yr}$ since the Meiji era.

\section{Associations with Estimated Breeding Values}

Boettcher et al. (1996) suggested that mutations at the rRNA and D-loop regions of the mitochondrial genome affect performance traits of dairy cattle. So it is of interest to compare milking performance traits between mitochondrial genotypes. Here we analyzed for association between EBV for performance traits and mitochondrial genotype using 1351 cows from the Chiba and Hyogo regions. The analysis conducted here was not designed to detect the effect of mitochondrial genome itself because EBV represented the additive genetic effect of nuclear genome. However the mitochondrial genotype could be regarded as an indicator of the cows' origin and the analysis of EBV would reveal whether the grading up for the native cows was successfully accomplished.

Mitochondrial genotypes of 758 animals from the Chiba region and 582 animals from the Hyogo region 
TRACE OF NATIVE CATTLE IN JAPANESE HOLSTEIN

Table 2. Least square means and standard errors of estimated breeding values ${ }^{1}$ for performance traits by regions and mitochondrial types. ${ }^{2}$

\begin{tabular}{|c|c|c|c|c|c|c|c|c|}
\hline Effect & $\mathrm{N}$ & $\begin{array}{l}\text { Milk yield } \\
\quad(\mathrm{kg})\end{array}$ & $\begin{array}{l}\text { Fat } \\
(\mathrm{kg})\end{array}$ & $\begin{array}{l}\text { Fat } \\
(\%)\end{array}$ & $\begin{array}{l}\text { Protein } \\
\quad(\mathrm{kg})\end{array}$ & $\begin{array}{l}\text { Protein } \\
(\%)\end{array}$ & $\begin{array}{l}\text { SNF } \\
(\mathrm{kg})\end{array}$ & $\begin{array}{c}\mathrm{SNF} \\
(\%)\end{array}$ \\
\hline \multicolumn{9}{|l|}{ Region } \\
\hline Chiba & 758 & $476.9 \pm 27.2^{\mathrm{a}}$ & $18.8 \pm 1.1^{\mathrm{a}}$ & $0.01 \pm 0.01$ & $12.5 \pm 0.8^{\mathrm{a}}$ & $-0.03 \pm 0.01^{\mathrm{a}}$ & $39.0 \pm 2.2^{\mathrm{a}}$ & $-0.04 \pm 0.01^{\mathrm{a}}$ \\
\hline \multicolumn{9}{|l|}{ Type } \\
\hline $\mathrm{BI}$ & 204 & $246.2 \pm 31.3$ & $7.5 \pm 1.3$ & $-0.02 \pm 0.01$ & $5.6 \pm 0.9$ & $-0.03 \pm 0.01$ & $19.7 \pm 2.6$ & $-0.02 \pm 0.01$ \\
\hline $\mathrm{S}$ & 1092 & $253.1 \pm 13.7$ & $9.6 \pm 0.6$ & $0.00 \pm 0.01$ & $6.4 \pm 0.4$ & $-0.02 \pm 0.00$ & $20.7 \pm 1.1$ & $-0.02 \pm 0.00$ \\
\hline
\end{tabular}

${ }^{1}$ Estimated data in August 2000.

${ }^{2}$ Means within an effect having different superscripts differ $(P<0.05)$.

were classified into 3 types using the PCR-RFLP method. Table 2 shows the results. Five animals from Chiba and 6 animals from Hyogo showed PCR-RFLP patterns that could not be classified into $\mathrm{B}$, I, or $\mathrm{S}$, so 153-bp fragments including the polymorphic sites of B and I from those animals were sequenced. We found that one fragment had a 3-bp deletion from nt16062 and the other fragment had a single nucleotide polymorphism at the Rsa I restriction site at nt16062. Those polymorphisms were different from the ones specific to the type B, I, and S polymorphisms, and so were removed from the analysis.

The number of animals with the type BI polymorphism was 204, or $15.2 \%$ (204/1340). This is similar to the values shown in Table 1 . Those results confirmed that a considerable number of Japanese Holstein cows have mitochondria that originated in native cattle.

The EBV of milking production traits were compared between cows that have the same mitochondria as pure Holsteins and cows that have mitochondria originating from native animals. Table 2 shows the least square means and their standard errors. Significant effects of regions were observed for all traits except for fat percentage. In contrast, the difference between mitochondrial genotypes was not significant for any trait.

It was expected that the native animals would have much lower performances than Holsteins regarding milk production traits. This result suggests that autosomal genes of native animals were successively replaced by those from pure Holsteins by grading up for over 15 generations. Finally, we found a considerable number of Japanese Holstein cows that had unique mitochondrial genotypes, with sequences not observed in European breeds, and we have evidence that these genotypes originated in native cows. The appearance of the same genotypes with European breeds in modern Japanese Holstein cattle suggests introgression of these genes over $120 \mathrm{yr}$ of selective breeding. However, no difference in milking performance was observed between animals originating from native cows and animals originating from pure Holstein. This information will be valuable in establishing grading up programs for dairy cattle in developing countries.

\section{ACKNOWLEDGMENTS}

We thank N. Cockett, Utah State University, and P. Boettcher, University of Guelph, Canada, for their kind cooperation in collecting hair samples from North American Holstein cows and thank T. Yoshizawa, the National Livestock Breeding Center (NLBC), for providing EBV of Japanese Holstein cows. We also thank G. H. Harper for his critical reading and comments for this manuscript.

\section{REFERENCES}

Anderson, S., M. H. L. deBruijn, A. R. Coulson, I. C. Eperon, F. Sanger, and I. G. Young. 1982. Complete sequence of bovine mitochondrial DNA. J. Mol. Biol. 156:683-717.

Boettcher, P. J., D. W. B. Steverink, D. C. Beitz, A. E. Freeman, and B. T. McDaniel. 1996. Multiple herd evaluation of the effects of maternal lineage on yield traits of Holstein cattle. J. Dairy Sci. 79:655-662.

Bradley, D. G., D. E. MacHugh, P. Cunningham, and R. T. Loftus. 1996. Mitochondrial diversity and the origins of African and European cattle. Proc. Natl. Acad. Sci. USA 93:5131-5135.

Higuchi, R., C. H. von Beroldingen, G. F. Sensabaugh, and H. A. Erlich. 1988. DNA typing from single hairs. Nature (Lond.) 332:543-546.

Loftus, R. T., D. E. MacHugh, D. G. Bradley, P. M. Sharp, and P. Cunningham. 1994a. Evidence for two independent domestications of cattle. Proc. Natl. Acad. Sci. USA 91:2757-2761.

Loftus, R. T., D. E. MacHugh, L. O. Ngere, D. S. Balain, A. M. Badi, D. G. Bradley, and E. Cunningham. 1994b. Mitochondrial genetic variation in European, African and Indian cattle populations. Anim. Genet. 25:265-271.

Mannen, H., S. Tsuji, R. T. Loftus and D. G. Bradley. 1998a. Mitochondrial DNA Variation and Evolution of Japanese Black Cattle (Bos taurus). Genetics 150:1169-1174.

Mannen, H., T. Kojima, K. Oyama, F. Mukai, T. Ishida, and S. Tsuji. 1998b. Effect of mitochondrial DNA variation on carcass traits of Japanese Black cattle. J. Anim. Sci. 76:36-41.

The Holstein Cattle Association of Japan. 1967. Pages 17-18 in Dairy Cattle of Japan: History of Holstein. (In Japanese). The Holstein Cattle Association of Japan, Tokyo.

Thomson, D. M., N. N. Brown, and A. E. Clague. 1992. Routine use of hair root or buccal swab specimens for PCR analysis: Advantages over using blood. Clin. Chim. Acta 207:169-174. 